\title{
A AUTODETERMINAÇÃO NOS NEGÓCIOS BIOJURÍDICOS: UMA NECESSÁRIA RELEITURA DA AUTONOMIA PRIVADA SOB O ASPECTO LIBERAL.
}

\author{
Aracelli Mesquita Bandolin Bermejo ${ }^{1}$ \\ Rita de Cassia Resquetti Tarifa Espolador ${ }^{2}$
}

\section{RESUMO}

O estudo aborda a evolução do negócio jurídico partindo das influências do Estado Liberal, avançando pelos contornos ditados pelo Estado Social e a Constitucionalização do Direito Privado. Mediante aplicação do método dedutivo, amparado na revisão jurídico-literária, chega-se à conclusão da necessidade de releitura de seus institutos para acolher interesses existenciais emergidos das novas técnicas biomédicas de disposição do corpo humano, ampliando o campo de liberdade individual a fim de reconhecer a autodeterminação como instituto essencial à plenitude do exercício dos direitos e interesses fundamentais, particulares e existenciais dos indivíduos.

Palavras-Chave: Interesses existenciais; Negócios Jurídicos Existências; Negócios biojurídicos; Interesses relevantes; Autodeterminação; Liberdade positiva.

\section{SELF-DETERMINATION IN BIOJURICIAL BUSINESS: A NECESSARY RELEASE OF PRIVATE AUTONOMY UNDER THE LIBERAL ASPECT.}

\begin{abstract}
The study deals with the evolution of the legal business starting from the influences of the Liberal State, advancing along the lines dictated by the Social State and the Constitutionalisation of Private Law. By applying the deductive method, based on the legalliterary review, the conclusion is reached of the need to reread its institutes to welcome existential interests emerging from the new biomedical techniques of human body disposition, extending the field of individual freedom in order to recognize Self-determination as an essential institute to the full exercise of the fundamental rights, interests and individuals.
\end{abstract}

Keys-word: Existential interests; Legal Business Stocks; Biojuridic business; Relevant interests; Self-determination; Positive freedom.

\section{INTRODUÇÃO}

A realidade da sociedade atual é marcada por avanços tecnológicos nas mais diversas áreas, cujos reflexos, invariavelmente, atingem o Direito. No campo da medicina e da biologia

\footnotetext{
${ }^{1}$ Mestranda em Direito Negocial da UEL. Bolsista CAPES.

${ }^{2}$ Profa. Doutora do Departamento de Direito Privado da UEL e do Programa de Mestrado em Direito Negocial da UEL.
} 
surgiram inúmeras possibilidades conferidas ao ser humano, nas quais o homem passou a ter condições fáticas de decidir sobre como dispor do próprio corpo.

Somado a isso, com a Constituição Federal de 1988 e o movimento da constitucionalização do Direito Civil, fortalecido com o atual Código, houve uma mutação cultural, colocando o ser humano no centro das relações jurídicas e atribuindo ainda mais relevância à valoração moral-social, inclusive, no debate sobre questões atinentes ao começo e fim da vida.

Questões como direito a uma morte justa e digna e novas formas de nascimento passam a ser enfrentadas, colidindo, aparentemente, com uma sociedade extremamente pluralista, com posições culturais, éticas, morais e religiosas completamente distintas.

No presente estudo, será abordada a necessidade de releitura da autonomia privada nas decisões de começo e fim da vida sob o prisma da liberdade individual.

Dentro desse contexto, será analisado, ainda que em breves linhas, o conceito de negócio jurídico, considerando as várias vertentes em torno do elemento vontade utilizadas para definição, a evolução da autonomia da vontade, permeando pela autonomia privada e chegando na autodeterminação ditada pelos referenciais bioéticos, especialmente pelo da autonomia.

Através do método dedutivo e pesquisa bibliográfica, chegará à conclusão de que a autonomia privada deve ser analisada sob a perspectiva individualista, focando nos seus interesses mais íntimos e sensíveis, e, quando feita a opção por abreviação do sofrimento, ceifando a vida de forma artificial ou projetando o nascimento através de reprodução humana assistida, dentre outras decisões que se restringem à própria existência da pessoa, seja reconhecida a sua liberdade de escolha e de se manter digno, buscando meios de que a decisão seja legitimada através de consentimento livre, esclarecido e plenamente informado.

\section{DOS NEGÓCIOS JURÍDICOS E A IMPORTÂNCIA DA VONTADE NA SUA FORMAÇÃO}

Para que se possa compreender o objeto principal deste estudo, não se pode furtar da análise, ainda que breve e sem adentrar nos pormenores, do conceito de negócio jurídico.

Os negócios jurídicos de maneira geral são provenientes do exercício da autonomia privado de titulares de interesses relevantes juridicamente. 
$\mathrm{O}$ art. 104 do Código Civil exige para constituição de um negócio jurídico os seguintes elementos: partes, objeto e vontade (manifestada na forma livre ou prescrita em lei)

O elemento vontade está diretamente relacionado ao próprio conceito de negócio jurídico, de forma que as concepções deste termo variam conforme duas correntes: a voluntarista e a objetivista (GOMES, 1971, p. 249).

Pela teoria voluntarista, defendida por Clóvis Bevilaqua, Washington de Barros Monteiro, Orlando Gomes, dentre outros, os negócios jurídicos são entendidos como uma manifestação de vontade visando a produção de efeitos jurídicos (AZEVEDO, 2014, p. 5). Por outro lado, a teoria objetivista, defendida por Emílio Betti, dá foco na função do negócio jurídico, compreendendo-o como fator de produção de efeitos jurídicos (AZEVEDO, 2014, p. 11).

Antônio Junqueira de Azevedo não adere às definições dos demais autores com base na teoria voluntarista, que remete à genética do negócio jurídico, nem na teoria objetivista que remete à função do instituto. Para o autor, deve-se buscar a definição em sua estrutura (AZEVEDO, 15).

O negócio jurídico, estruturalmente, pode ser definido ou como categoria, isto é, como fato jurídico abstrato, ou como fato, isto é, como fato jurídico concreto.

Como categoria, ele é a hipótese de fato jurídico (às vezes dita "suporte fático), que consiste em uma manifestação de vontade cercada de certas circunstancias (as circunstancias negociais) que fazem com que socialmente essa manifestação seja vista como dirigida à produção de efeitos jurídicos; negócio jurídico como categoria é, pois, a hipótese normativa consistente em declaração de vontade (entendida como expressão em sentido preciso, e não comum, isto é, entendida como manifestação de vontade que, pelas circunstâncias, é vista socialmente como destinada à produção de efeitos jurídicos. Ser declaração de vontade é a sua característica específica (...).

In concreto, negócio jurídico é todo fato jurídico consistente em declaração de vontade, a que o ordenamento jurídico atribui os efeitos designados como queridos, respeitados os pressupostos de existência, validade e eficácia impostos pela norma jurídica que sobre ele incide (AZEVEDO, 2014, p. 16).

Como se pode notar, o elemento vontade consta nas mais diversas correntes que definem o negócio jurídico, tamanha é sua importância, fazendo surgir a dualidade clássica de correntes também em relação ao que se entende por vontade para fins de sua conceituação: Teoria da Vontade e Teoria da Declaração. 
A Teoria da Vontade reinante, sobretudo, no direito francês, o qual é essencialmente psicológico, faz prevalecer a vontade verdadeira do declarante, reconhecendo que somente essa vontade deve ser levada em consideração para fins de atribuição de efeitos jurídicos (AZEVEDO, 2014, p. 74-75).

A Teoria da Declaração, adotada pelo direito alemão, preocupado essencialmente com a segurança das relações contratuais, reconhece como válida a produzir efeitos a vontade declarada e não a vontade psíquica do agente (AZEVEDO, 2014, p. 74-75).

Para a Teoria da Declaração

$\mathrm{Na}$ verdade, a "vontade", como fato psicológico meramente interno, é qualquer coisa em si mesma incompreensível e incontrolável, e pertence, unicamente, ao foro íntimo da consciência individual. Só na medida em que se torna reconhecível no ambiente social, quer por declarações, quer por comportamentos, ela passa a ser um fato social, susceptível de interpretação e de valoração por parte dos consorciados. Somente declarações ou comportamentos são entidades socialmente reconhecíveis e, portanto, capazes de poder constituir objeto de interpretação, ou instrumento de autonomia privada. (BETTI, 2008, p 89).

É no âmbito da interpretação dos negócios jurídicos que a distinção dessas teorias ganha mais significado (AZEVEDO, 2014, p. 89), sendo que a tendência jurídica e normativa brasileira é no acolhimento de ambas as teorias, de forma que não haverá o predomínio absoluto da vontade interna, porém, reconhece-se que esta não pode ser ignorada.

Essas teorias não se podem aplicar unilateralmente, mas combinadas de modo que o intérprete estabeleça, em face da declaração e de suas circunstancias, qual seja, objetivamente, a vontade real do declarante.

A interpretação que adotar o critério subjetivo, procurando a intenção pura dos declarantes, desenvolverá uma pesquisa histórica, visando reconstruir o pensamento e os objetivos dos declarantes. Já a interpretação que adote o critério objetivo, buscará um sentido, um significado preciso, concreto, contido na declaração negocial, independente da vontade psicológica dos agentes. (AMARAL, 2014, p. 458).

Deve-se aplicar tanto a teoria da vontade quanto a da declaração, em conjunto.

Parte-se da declaração, que é forma de exteriorização da vontade, para se apurar a real intenção das partes. Esta deve, pois, ser considerada, não no sentido de pensamento íntimo dos declarantes, pois não se buscam os seus motivos psicológicos, mas sim no sentido mais adequado a uma 
interpretação que leve em conta a boa-fé, o contexto e o fim econômico do negócio jurídico (GONÇALVES, 2013, p. 324).

É indissociável do estudo do negócio jurídico o estudo da vontade, seja ela a vontade psíquica ou a declaração da vontade, as quais, estão, por sua vez, intimamente relacionadas com a liberdade de agir.

A possibilidade de a pessoa agir de acordo com sua vontade, podendo fazer ou deixar de fazer algo, chama-se liberdade, que, sendo conceito plurívoco, extremamente complexo, compreende várias espécies, como a liberdade natural, a social ou política, a pessoal e a jurídica, que é a que nos interessa (AMARAL, p. 408-409).

A liberdade jurídica é compreendida como aquela exercida pelo sujeito e capaz de produzir efeitos jurídicos desejados, ou seja, capaz de criar, modificar ou extinguir relações jurídicas (AMARAL, 409), cujos limites vão variar conforme o ponto de análise, havendo distinção quando se tratar de autonomia da vontade, autonomia privada e autodeterminação.

Quando se trata de Biodireito o campo de autonomia privada é ainda objeto de embate jurídico, falando-se em autodeterminação, na qual há maior liberdade de disposição do próprio corpo.

É indissociável, portanto, a vontade da constituição de um negócio jurídico e, via de consequência, a vontade é diretamente relacionada com a liberdade a que se sujeita o indivíduo de dispor.

O presente estudo visa contribuir para uma análise dos limites dessa liberdade quando relacionada aos negócios biojurídicos.

\section{A MUDANÇA DE PERSPECTIVA NA HISTÓRIA DA LIBERDADE}

O conceito de liberdade varia conforme o momento histórico vividos e estudado.

Para os antigos, a liberdade consistia num atributo político dos cidadãos para participar ativamente da vida pública, visando o bem comum e não interesses privados. Viviam num contexto claro de submissão à autoridade política, em que deliberar em praça pública sobre a guerra e a paz, a votação de leis, bem como a deliberação de atos administrativos era o conceito pleno de liberdade. Nesta época, via-se na guerra uma forma eficaz de amealhar riquezas, terras e poder (CANEZIN; PIVATO, 2016, p. 199) 
Esse conceito de liberdade, passou a ser considerado insuficiente na sociedade moderna, marcada por direitos subjetivo individuais (RAMOS, 2007, p. 301-302). Com a ascensão da burguesia, novas fontes de riquezas foram surgindo e o sentimento individualista foi se fortalecendo, de forma que o ser humano passou a buscar cada vez mais a satisfação dos anseios individuais e não mais coletivos (CONSTANT, 1985, p.14).

Atualmente, o termo liberdade remete não mais à liberdade coletiva na busca do bem comum como outrora, mas na liberdade privada de cada indivíduo.

Da breve explanação, é possível verificar que o conceito de liberdade reflete sobremaneira na autonomia negocial, cujos limites de feição variam conforme os cenários jurídicos já vivenciados durante os tempos e que revestiram a formação dos negócios jurídicos.

A sociedade contemporânea demanda tutelas jurídicas fundadas em interesses cada vez mais complexos, representando grande inovação a proteção de interesses existenciais, tornando-os passíveis de serem objetos de negócios jurídicos.

Esses interesses, contudo, clamam por maior amplitude na liberdade de dispor do corpo humano, indo de encontro com a doutrina e previsões legais clássicas nas quais havia impedimento, que visavam, substancialmente, a proteção do indivíduo, e hoje, na prática, é justamente o indivíduo que, voltado aos interesses mais particulares, busca ampliar o campo de disposição.

É neste cenário que se passa ao estudo da evolução da autonomia negocial, partindo da autonomia da vontade até chegar ao conceito atual de autodeterminação.

\section{DA AUTONOMIA DA VONTADE À AUTODETERMINAÇÃO: UMA EVOLUÇÃO DOS LIMITES DA LIBERDADE}

Para que se possa ter uma visão global da necessidade de elasticidade dos limites da liberdade, especialmente, da liberdade negocial nos negócios biojurídicos, é importante analisar a evolução jurídica pela qual caminhou a autonomia da vontade, passando pela autonomia privada e chegando, nos moldes contemporâneos, na autodeterminação.

A amplitude dos negócios jurídicos sofreu grandes interferências das mudanças de formas de Estado passadas pela sociedade influenciando sobremaneira na liberdade de decisão 
individual, a qual é diretamente relacionada com a autonomia e liberdade de agir e ser de cada um.

Como reação ao Estado Totalitário, o Estado Liberal traçou evidentes contornos e limites ao direito público e ao direito privado, pregando a defesa do individualismo como pressuposto do liberalismo, (BOBBIO, 2005, p. 16), refletindo sobremaneira no direito negocial, no qual foi reconhecida, de forma absoluta, a autonomia da vontade, consagrando o princípio da força obrigatória dos contratos (PEREIRA, 1978, p. 21).

Os negócios jurídicos inseridos nesse contexto eram eminentemente patrimonialistas, colocando os sujeitos de forma abstrata na relação formada, deixando seus interesses e necessidades em segundo plano, afastando elementos importantes como a busca do equilíbrio contratual (FACHIN, 2012, p. 101).

Com a entrada do Código Civil de 2002 e o despertar da chamada Constitucionalização do Direito Civil, iniciou-se nova era para os negócios jurídicos inseridos no Estado Social, no qual a autonomia da vontade, cuja conotação é subjetiva e diz respeito à possibilidade de seu titular firmar ou não os negócios jurídicos, é reavaliada e dá lugar à autonomia privada, como poder dos titulares de regular o conteúdo e disciplina dos negócios nos quais fizerem parte (AMARAL, 2003, p. 337-338).

Neste caminhar da evolução da sociedade e com o surgimento de situações jurídicas em que interesses personalíssimos são postos em cheque, como nas decisões de fim da vida e de gestação por substituição, em que há aparente colisão entre direito à vida, liberdade, dignidade da pessoa humana, etc., a autonomia privada novamente passa por uma releitura necessária para que efetivamente seja albergada pelos anseios numa relação justa e razoável de novas relações surgidas.

Vislumbra-se, então, a figura da autodeterminação, cujos limites são mais amplos e se referem à amplitude reconhecida à autonomia privada.

O sentido aqui entendido como autonomia privada, nesse primeiro momento, seria o pensado por Kant, de agir racionalmente buscando através de valores universais as escolhas corretas para a sua felicidade, e será essa possibilidade de autodeterminação que irá revela-se como autodeterminação. Seria uma vontade livre de toda a causalidade e determinação estranha, sendo vista como uma verdadeira autonomia, uma autolegislabilidade da vontade (Hoffe, 2005, P.220) (PEREIRA, 2017, p. 227). 
A autodeterminação, portanto, pode ser compreendida no poder que o indivíduo tem de se autoregulamentar, sem que haja interferências externas, inclusive estatal e sua importância no Biodireito se deve justamente pelo objeto negocial, ou seja, interesses personalíssimos.

Assim, como se pode notar, tanto o termo liberdade como o exercício dela foram objeto de aprofundamento e modificações histórias, passando a primeira de um caráter coletivo para individual e o segundo, seguindo um transito da autonomia da vontade para autonomia privada e chegando, contemporaneamente, na autodeterminação

\title{
4 AUTODETERMINAÇÃO NOS NEGÓCIOS BIOJURÍDICOS
}

Com os avanços da biotecnologia surgiram inúmeras possibilidades fáticas de disposição do corpo humano, sem prejuízo para a pessoa e, via de consequência, fez surgir o interesse jurídico na sua utilização como objeto de negócios jurídicos.

\begin{abstract}
A biotecnologia está no cerne dessa questão, na medida em que possibilita a escolha sobre aspectos do próprio corpo que podem promover efeitos constitutivos, modificativos ou extintivos. Nesses casos, conforme antes mencionado, a autonomia privada ganha a forma de negócio jurídico. Como têm por referencial objetivo aspectos da saúde e do corpo do declarante, foram aqui chamados de biojurídicos (MEIRELES, 2017, p. 115)
\end{abstract}

Diante da releitura dos negócios jurídicos a fim de acolher os negócios biojurídicos, cujo caráter é eminentemente existencial e particular, a liberdade de atuação dos sujeitos deve seguir a mesma sorte.

\begin{abstract}
A autonomia privada passa a ser vista com base na sua concepção bioética, atrelada à capacidade de decisão livre sobre os objetivos pessoais, amparada num consentimento livre, esclarecido e informado, devendo "ser respeitada a liberdade de escolha do paciente, seu direito de autodeterminação, de manifestação livre de sua vontade, de sua privacidade" (PONA, 2015, p. 157).
\end{abstract}

A bioética surgiu nos últimos 40/45 anos como resultado de uma releitura da ética médica-científica tradicional e representada pelo elo entre ciência biológica e a ética, cujo fundamento é a preocupação de que a sobrevivência de grande parte da espécie humana, numa 
civilização sustentável, dependia do desenvolvimento e manutenção de um sistema ético (SOUZA; SOCZEK, 2009, p. 397).

Como resultado da reflexão bioética, foram identificados 4 princípios que fundamentam o caminhar da sociedade em terreno de biomedicina: autonomia, beneficência, não maleficência e justiça.

Para o objeto do presente estudo fazer-se-á um recorte abrangendo somente a autonomia, pois, como mencionado alhures, é a concepção bioética do termo que deve ser considerada para fins de disciplinar condutas através de negócios biojurídicos.

A autonomia como referencial bioético reconhece a capacidade da pessoa, inclusive na qualidade de paciente, de autogovernar-se, devendo serem respeitadas suas crenças religiosas e morais (DINIZ, 2014, p. 38).

Esta concepção surgiu como reação ao antigo paternalismo médico marcado pela presunção de que o doente seria sempre incapaz de tomar decisões autônomas. Em meados do século XX, notou-se, primeiramente nos Estados Unidos, o aumento de litígios e condenações envolvendo médicos, os quais eram punidos por desrespeitarem as decisões dos seus pacientes, declarando o dever dos profissionais em acolher a vontade manifestada (NEVES, SIQUEIRA, 2010, p. 443).

No entanto, a liberdade reconhecida não é absoluta, mas possui limitações que visam salvaguardar pacientes quando a manifestação de vontade declarada não for adequada ou aparentar vício, até mesmo por falta de conhecimento técnico, colocando-o em situação de vulnerabilidade semelhante, ainda que no extremo inverso, do paternalismo médico combatido (NEVES, SIQUEIRA, 2010, p. 443).

No Brasil, o Código de Ética Médica, aprovado pelo Conselho Federal de Medicina em $2009^{3}$, prevê em seu inciso XXI o princípio da autonomia do paciente, de forma ponderada, sendo, doutrinariamente defendido que o exercício da autonomia privada seja amparado por declaração de vontade real, sólida e verdadeira, devendo cumprir dois requisitos: o consentimento livre e esclarecido e a possibilidade de tomar decisões de substituição quando impossibilitado de tomar por si próprio (DINIZ, 2014, p. 39).

\footnotetext{
${ }^{3}$ Inciso XXI: No processo de tomada de decisões profissionais, de acordo com seus ditames de consciência e as previsões legais, o médico aceitará as escolhas de seus pacientes, relativas aos procedimentos diagnósticos e terapêuticos por eles expressos, desde que adequadas ao caso e cientificamente reconhecidas. (Conselho Federal de Medicina. Código de Ética Médica 2009: Resolução CFM nº 1.931/2009. Brasília: CFM, 2009).
} 
A exigência para o exercício da autonomia bioética se refere à esfera individual do sujeito e, uma vez cumprida, lhe confere liberdade de dispor da forma que melhor entende possível para si, sendo os negócios biojurídicos um instrumento de disposição e regulação desses interesses.

Verifica-se, portanto, que o próprio elemento constituidor dos negócios jurídicos, ou seja, a vontade manifestada, acolhe absolutamente, em terreno de Biodireito, o referencial bioético, podendo este ser considerado como elemento essencial para a formação dos negócios biojurídicos.

Everton Pona transcreve o ensinamento de Rachel Sztajn para a qual a autonomia privada da bioética não é imposta a outro ser humano, mas sim diz respeito à privacidade, está na raiz da dignidade humana devendo ser reconhecida nos negócios biojurídicos (apud PONA, 2015, p. 157). "O que ocorre no e com o corpo do indivíduo, segundo essa perspectiva, está sujeito à exclusiva esfera de deliberação do próprio titular" cuja "autodeterminação tem potencial para criar, modificar ou extinguir relações ou situações" (PONA, 2015, p. 158).

Essa perspectiva é inerente à própria proteção à personalidade do indivíduo, pois a "realização completa da personalidade só se torna possível, então, quando as normas fixadas pelo indivíduo na tutela dos seus interesses mais íntimos são respeitadas" (PONA, 2015, p. 159).

\begin{abstract}
A noção de autonomia privada como capacidade de autodeterminação do sujeito de direito remonta à ideia kantiana de legislador de si próprio. Nessa concepção, a autonomia privada se caracteriza pelo poder de fazer escolhas e diferenciações, e de as fazer, não conforme critérios objetivos - de conveniência econômica, de razoabilidade, de igualdade social etc. -, mas, antes, segundo o livre arbítrio do sujeito (PINTO, 2006, p. 382). Os projetos de vida de cada ser humano, portanto, são protegidos por essa autonomia (LIMA; PEGORER, 2017, p. 187).
\end{abstract}

Como visto, a autodeterminação possui vasto campo de disposição para regulação de interesses dos indivíduos, sendo caracterizada justamente pela escassez de limites especialmente pelo fato de, no direito brasileiro, ser reconhecida principalmente quando atinentes a questões existenciais.

No entanto, é importante se estabelecer os limites da autodeterminação, sendo certo que conferir a liberdade absoluta ao indivíduo, especialmente diante das várias possibilidades 
fáticas de disposição no campo do Biodireito, pode gerar insegurança e, principalmente, utilizar das novas técnicas médicas e biológicas de forma desvirtuada, tendo em vista que esse ramo reserva grande segmento de seu campo de estudo para os conflitos advindos de técnicas de reprodução humana assistida e decisões de começo e fim da vida, sem que exista a correspondente normatização legal dos interesses dos sujeitos envolvidos nos procedimentos, ditando a necessária releitura de institutos da Teoria Geral do Direito, especialmente relativa aos Negócios Jurídicos, já que esses exercem substancial importância na regulação de conduta de envolvidos na situação relacional.

Mas então, como saber quais os limites da autodeterminação?

A resposta está justamente nos fatores de limitação da liberdade privada do indivíduo, a qual volta a ser discutida e, para se estabelecer eventuais limites é necessário, primeiramente, tecer o conceito do termo.

John Stuart Mill (apud PONA, 2015, p. 200) ao defender a liberdade individual, reconhece somente a limitação quando a justificativa recaia sobre a conduta ser danosa ou potencialmente danosa a terceiros ou à sociedade, de forma que, não invadindo a esfera alheia, não há legitimidade para restrição do âmbito de agir individual. Afasta, portanto, a delimitação do conteúdo fundada em padrão de comportamento moral e religioso e garante conteúdo mínimo que não permite qualquer interferência externa pois relacionado ao desenvolvimento natural das faculdades naturais do homem.

Para o filósofo liberal, o indivíduo é quem mais conhece o que é o melhor para si, de forma que a sociedade, mesmo com toda a reprovação moral ou social, não tem a capacidade de invadir a esfera íntima da pessoa.

Isaiah Berlin propõe a análise dos limites da liberdade partindo das seguintes questões: “qual é a área em que o sujeito - uma pessoa ou grupo de pessoas - é ou deve ter permissão de fazer ou ser o que é capaz de fazer ou ser, sem interferência de outras pessoas? " e "o que ou quem é a fonte de controle ou interferência capaz de terminar que alguém faça ou seja uma coisa em vez de outra?" (BERLIN, 2002, p. 228-229).

Em resposta aos questionamentos, apresenta a definição de liberdade negativa como sendo a ausência de ingerência externa na decisão individual de como, onde e quando agir ou ser; e de liberdade positiva, no sentido de ser o seu senhor, se conduzir pelas suas próprias razões e verdades, pautado no seu conhecimento (BERLIN, 2002, p. 237).

A liberdade negativa consiste em ser 
considerado livre na medida em que nenhum homem ou conjunto de indivíduos interfere com a minha atividade. A liberdade política neste sentindo é simplesmente a área dentro da qual um homem pode agir sem ser obstruído por outros. Se outros me impedem de fazer o que do contrário eu poderia fazer, não sou nessa medida livre; e, se essa área é restringida por outros homens além de certo valor mínimo, posso ser descrito como coagido ou, talvez, escravizado (BERLIN, 2002, p. 229).

Cesar Augusto Ramos (2006, p. 46) define a liberdade negativa como a ausência de impedimentos e afirma que "ser livre significa não sofrer a interferência de outrem e fazer tudo aquilo que as leis permitem".

No aspecto positivo a liberdade

provém do desejo que o indivíduo nutre de ser seu próprio senhor. Desejo que minha vida e minhas decisões dependam de mim mesmo, e não de forças externas de qualquer tipo. Desejo ser o instrumento de meus próprios atos de vontade, e não dos de outros homens. (...) Acima de tudo, desejo ser consciente de mim mesmo como alguém que age, tem vontade e pensa, responsável por minhas escolhas e capaz de explicá-las a partir de minhas ideias e meus propósitos (BERLIN, 2002, p. 237).

A contemporaneidade demonstra que a diversidade e a pluralidade da sociedade fomentam ainda mais a reflexão sobre a extensão da liberdade do indivíduo, cenário este ainda mais evidente quando visto sob o prisma do Biodireito, o qual, como já mencionado, traz situações delicadas, novas, inimagináveis e polêmicas.

Essas situações biojurídicas, embora possam ter reflexos sociais e/ou a terceiros, se referem especialmente à interesses individuais e particulares, justificando o reconhecimento de maior liberdade para disposição do próprio corpo ou parte dele, dentro de um conceito de liberdade positiva.

No sentido positivo, a liberdade é compreendida como a capacidade de autodeterminação do indivíduo, por meio da autonomia da vontade. De inspiração rousseauista, esse conceito de liberdade opera como a ideia de autonomia da vontade. Ela é positiva, porque indica a presença de uma faculdade de volição que decide (a vontade autônoma), mediante a qual o indivíduo age e escolhe sempre de acordo com as preferenciais racionais sobre como ele deve, livremente, viver. Neste sentido, a liberdade significa o desejo de o indivíduo ser senhor de si próprio e de sua atividade (RAMOS, 2011, p. 47). 
A autodeterminação deve, portanto, ser guiada pelo conceito de liberdade individual, respeitando-se ao menos o essencial para que o indivíduo possa exercer plenamente sua existencialidade.

Visando conciliar a proteção de direitos fundamentais e as diferenças dos indivíduos, Ronald Dworkin propõe uma Teoria da Liberdade, distinguindo-a em dois termos: freedom e liberty. A primeira corresponde à liberdade de agir sem a intervenção do governo, sendo a segunda, restrita à parcela da liberdade (freedom) na qual o governo erraria se intervisse (DWORKIN, 2015, p. 471).

A teoria de Dworkin que melhor enquadra a situação jurídica contemporânea relativa a questões do biodireito, pois a diversidade de procedimentos biológicos e faticamente possíveis de serem realizados, muitas vezes, encontram obstáculos para serem reconhecidos em virtude de padrões de comportamento ditados pela moral e religião, porém, afetam interesses particulares, fundamentais, personalíssimos dos indivíduos, sem que haja qualquer reflexo perante terceiros ou sociedade.

Seria o caso, por exemplo, de uma gestação através de útero alheio, no qual, um casal impedido fisiologicamente de gerar seus próprios filhos biológicos, recorre a uma mulher que cede o útero para gestação do bebê que, ao nascer, é entregue aos pais biológicos.

Embora esteja sendo praticado e reconhecido pelo ordenamento jurídico, muito se discute sobre a validade dos negócios jurídicos gestacionais com fundamento na ilicitude do objeto por ser considerado imoral.

Como se pode notar, os interesses envolvidos limitam-se à esfera individual dos envolvidos, os quais se sujeitam de forma consciente, refletida e esclarecida à situação jurídica fundada em interesses e direitos fundamentais e particulares de cada um, não havendo motivos para ingerência social ou governamental. Estamos diante da parcela de liberdade intocável, de uma liberty, da liberdade de autorregulação.

Nas escolhas existenciais, a tutela jurídica da autonomia privada deve ser reforçada, pois está ligada de maneira mais forte com a esfera particular e íntima do indivíduo sobre a qual resta pouco espaço de intervenção para o Estado. Nesse contexto, é possível citar as questões que envolvem disposição sobre consentimento para tratamentos médicos e, principalmente, decisão sobre o próprio corpo, como é o caso da discussão do aborto (LIMA; PEGORER, 2017, p. 188). 
Esse campo de liberdade mínima deve ser observado, afastando a ingerência do Estado ou de indivíduos estranhos à situação jurídica formada e, reforçando a tese aqui defendida com a lição de Ronald Dworkin

\begin{abstract}
Supõem, especialmente libertários como Locke e Mill na Inglaterra, e Constant e Tocqueville na França, que exista certa área mínima de liberdade pessoal que não deve ser violada de modo algum, pois, do contrário, o indivíduo se verá numa área demasiado estreita até para aquele desenvolvimento mínimo de suas faculdades naturais que é o único a possibilitar a busca, e até a concepção, dos vários fins que os homens consideram bons, corretos ou sagrados (BERLIN, 2002, p. 231).
\end{abstract}

A esfera da liberdade individual, especialmente quando relativa a atos de disposição do próprio corpo, seja na tomada de decisões em prol do começo ou fim da vida, não afeta interesses alheios, mas sim, interesses dos sujeitos que se propõe à situação jurídica por livre, espontânea e consciente vontade, não havendo motivo que justifique a intervenção do Estado. A limitação somente seria justificada por padrões éticos e morais, tendo em vista se tratar da natureza humana, cujas pesquisas vão ao longo e, caso não ponderada, podem conduzir a humanidade por caminhos sem rumo.

\title{
CONCLUSÃO
}

Pensar no ser humano, no começo e, principalmente, no fim de sua vida, atribuindo feição jurídica para decisões tomadas por pacientes com doenças terminais ou no anseio da possibilidade de realização do sonho de procriar, obrigada a pensar temas polêmicos relativos ao campo de liberdade individual e a abstenção do Estado como limitador.

Diante dessa disparidade, a doutrina tem massivamente defendido a releitura dos institutos dos negócios jurídicos, ampliando o conceito de autonomia privada e falando-se na autodeterminação, delimitando-a no campo mínimo, ligado a interesses individuais, particulares, que não podem sofrer ingerência estatal ou de terceiros, visando o exercício da existencialidade humana em sua plenitude.

Com a ampliação da liberdade negocias nesses negócios existenciais, retoma-se a discussão acerca dos limites da liberdade individual.

Após a construção de um pensamento transitando pela evolução do termo liberdade e da autonomia da vontade até chegar na contemporânea autodeterminação, chega-se à 
conclusão de que certamente os limites de disposição do sujeito devem ser ampliados quando voltados exclusivamente aos interesses personalíssimos e existenciais.

Desta feita, considerando que os negócios biojurídicos são voltados essencialmente a questões existenciais, que não invadem interesses de terceiros mais tão somente interesses íntimos, particulares da própria existência do sujeito, não se pode conceber ingerência do Estado, exceto quando a conduta a ser praticada violar regras morais e éticas.

Tal limitação não busca cercear a liberdade negocial do indivíduo, mas proteger não somente ele, como toda a sociedade, da utilização maléfica das técnicas biomédicas, as quais, bem usadas, garantem a satisfação de desejos e sonhos mais delicados, porém, mal utilizadas, podem traçar um caminho sem volta.

\section{REFERÊNCIAS BIBLIOGRÁFICAS}

AMARAL, Francisco. Direito civil: introdução. 5. ed. rev., atual. e aum. Rio de Janeiro: Renovar, 2003.

AZEVEDO, Antonio Junqueira de. Negócio Jurídico: Existência, Validade e Eficácia. $4^{\mathrm{a}}$ ed. São Paulo: Saraiva, 2002.

BERLIN, Isaiah. Dois Conceitos de Liberdade. In: Estudos sobre a Humanidade: uma antologia de ensaios. Tradução Rosaura Eichenberg. São Paulo: Companhia das Letras, 2002.

BETTI, Emilio. Teoria do Negócios Jurídico. Trad. Servanda Editora. Campinas-SP: Servanda Editoda, 2008.

BOBBIO, Norberto. Liberalismo e democracia. Trad. de Marco Aurélio Nogueira. 6. ed. São Paulo: Brasiliense, 2005.

CANEZIN, Thays Cristina Carvalho; PIVATO, Marcilei Gorini. Direito e a Liberdade: A Construção do Significado de Liberdade no Cenário Internacional. In Direito Internacional em Expansão. Volume IX. Organizador: Wagner Menezes. Belo Horizonte: Arraes Editores, 2016, p. 196-204. 
Gonçalves, Carlos Roberto. Direito Civil Brasileiro v. 3. São Paulo: Saraiva, 2013.

CONSTANT, Benjamin. Da liberdade dos antigos comparada à dos modernos. In: MONTEIRO, João Paulo. Filosofia Política 2. Porto Alegre: L\&PM Editores (UNICAMP/UFRGS - com apoio do CNPQ), 1985. 9-2

DINIZ, Maria Helena. Compêndio de introdução à ciência do direito. 20. ed. rev. e atual. São Paulo: Saraiva, 2009.

FACHIN, Luiz Edson. Teoria crítica do direito civil. 3. ed. Rio de Janeiro: Renovar, 2012.

GOMES, Orlando. Introdução ao Direito Civil. $3^{\text {a }}$ ed. Rio de Janeiro: Forense, 1971.

LIMA, Jairo Néia; PEGORER, Mayara Alice Souza. Autonomia das Mulheres em Tempos de Zica Vírus: Uma perspectiva sobre o abordo a partir dos direitos sexuais e reprodutivos. In: Negócio Jurídico e Liberdades Individuais - Autonomia Privada e Situações Jurídicas Existenciais. Coordenadores: Éverton Willian Pona, Ana Cláudia Corrêa Zuin Mattos do Amaral e Priscila Machado Martins. Paraná: Juruá Editora, 2017.

MEIRELES, Rose Melo Venceslau. Negócios Biojurídicos. In: Negócio Jurídico e Liberdades Individuais - Autonomia Privada e Situações Jurídicas Existenciais. Coordenadores: Éverton Willian Pona, Ana Cláudia Corrêa Zuin Mattos do Amaral e Priscila Machado Martins. Paraná: Juruá Editora, 2017.

NEVES, Nedy Maria Branco Cerqueira; SIQUEIRA, José Eduardo de. A bioética no atual Código de Ética Médica. Revista Bioética 2010; 18 (2): 439 - 50.

PEREIRA, Caio Mário da. Instituições de direito civil. Rio de Janeiro: Forense, 1978.

PONA, Éverton Willian. Testamento vital e autonomia privada: fundamentos das diretivas antecipadas da vontade. Curitiba: Juruá, 2015.

RAMOS, Cesar Augusto. O modelo liberal e republicano de liberdade: Uma escolha Disjuntiva. Trans/formação. São Paulo $\quad$ - SP, v. $34, \quad$ n. 1.2011. <http://www2.marilia.unesp.br/revistas/index.php/transformacao/article/view/1045/944>. Acesso em 26/01/2017. 
SOUZA, Simonia; SOCZEK, Daniel. Bioética: a Baliza entre o Direito, o Avanço

Biocientífico e a Vida Humana. In: Estudos de Direito Internacional. Vol. XVI. Anais do 7Congresso Brasileiro de Direito Internacional. Coord: Wagner Menezes. Paraná: Juruá Editora. 2009. 